\title{
Cigarette Smoking and Carotid Plaque Echodensity in the Northern Manhattan Study
}

\author{
Dixon Yang ${ }^{a}$ Sunil lyer ${ }^{a}$ Hannah Gardener ${ }^{a}$ David Della-Morte ${ }^{a, c}$ \\ Milita Crisby ${ }^{d}$ Chuanhui Dong ${ }^{a}$ Ken Cheung $^{b}$ Consuelo Mora-McLaughlin ${ }^{b}$ \\ Clinton B. Wright ${ }^{\mathrm{a}}$ Mitchell S. Elkind $^{\mathrm{b}}$ Ralph L. Sacco ${ }^{\mathrm{a}}$ Tatjana Rundek $^{\mathrm{a}}$ \\ ${ }^{a}$ Department of Neurology, Miller School of Medicine, University of Miami, Miami, Fla., ${ }^{b}$ Department of Neurology, \\ College of Physicians and Surgeons and Department of Epidemiology, Mailman School of Public Health, Columbia \\ University, New York, N.Y., USA; ' Department of Systems Medicine, School of Medicine, University of Tor Vergata, \\ Rome, Italy; ${ }^{d}$ Department of Neurobiology, Care Sciences and Society, Karolinska Institutet, Stockholm, Sweden
}

\section{Key Words}

Smoking · Carotid plaque morphology · Carotid

ultrasound. Gray-scale median

\begin{abstract}
Background: We sought to determine the association between cigarette smoking and carotid plaque ultrasound morphology in a multiethnic cohort. Methods: We analyzed 1,743 stroke-free participants (mean age $65.5 \pm 8.9$ years; $60 \%$ women; $18 \%$ white, $63 \%$ Hispanic, $19 \%$ black; $14 \%$ current and 38\% former smokers, $48 \%$ never smoked) from the Northern Manhattan Study using an ultrasound index of plaque echodensity, the Gray-Scale Median (GSM). Echolucent plaque (low GSM) represents soft plaque and echodense (high GSM) more calcified plaque. The mean GSM weighted by plaque area for each plaque was calculated for those with multiple plaques. Quintiles of GSM were compared to no plaque. Multinomial logistic regression models were used to assess associations of cigarette smoking with GSM, adjusting for demographics and vascular risk factors. Results: Among subjects with carotid plaque (58\%), the
\end{abstract}

(C) 2015 S. Karger AG, Basel

$1015-9770 / 15 / 0404-0136 \$ 39.50 / 0$ mean GSM scores for quintiles $1-5$ were $48,72,90,105$, and 128 , respectively. Current smokers had over a two fold increased risk of having GSM in quintile 1 (odds ratio $(\mathrm{OR})=$ 2.17; 95\% confidence interval $(\mathrm{Cl}), 1.34-3.52)$, quintile 2 $(\mathrm{OR}=2.33 ; 95 \% \mathrm{Cl}, 1.42-3.83)$, quintile $4(\mathrm{OR}=2.05 ; 95 \% \mathrm{Cl}$, 1.19-3.51), and quintile $5(\mathrm{OR}=2.13 ; 95 \% \mathrm{Cl}, 1.27-3.56)$ but not in quintile $3(\mathrm{OR}=1.18 ; 95 \% \mathrm{Cl}, 0.67-2.10)$ as compared to never smokers in fully adjusted models. Former smokers had increased risk in quintile $2(\mathrm{OR}=1.46 ; 95 \% \mathrm{Cl}, 1.00-2.12)$, quintile $3(\mathrm{OR}=1.56 ; 95 \% \mathrm{Cl}, 1.09-2.24)$, quintile $4(\mathrm{OR}=1.66$; $95 \% \mathrm{Cl}, 1.13-2.42)$, and quintile $5(\mathrm{OR}=1.73 ; 95 \% \mathrm{Cl}, 1.19-$ $2.51)$, but not in quintile $1(\mathrm{OR}=1.05 ; 95 \% \mathrm{Cl}, 0.72-1.55)$. Conclusions: A nonlinear, V-shaped-like relationship between current cigarette smoking and plaque echodensity was observed. Former smokers were at the highest risk for plaques in high GSM quintiles. Thus, current smokers were more likely to have either soft or calcified plaques and former smokers were at greater risk of having only echodense plaques when compared to those who have never smoked. Further research is needed to determine if plaque morphology mediates an association between smoking and clinical vascular events.

\section{KARGER 125}

E-Mail karger@karger.com www.karger.com/ced
Tatjana Rundek, MD, $\mathrm{PhD}$

Department of Neurology, Miller School of Medicine University of Miami, Clinical Research Building, CRB 1348 1120 NW 14th Street, Miami, FL 33136 (USA)

E-Mail trundek@med.miami.edu 


\section{Introduction}

Cigarette smoking is a significant risk factor for atherosclerotic vascular disease [1]. Studies have linked current cigarette smoking to increased carotid intima-media thickness (IMT) [2], endothelial dysfunction [3], reduced flow-mediated dilation, and carotid plaque [1], ultimately leading to an increased risk of ischemic stroke $[4,5]$.

Moreover, the cumulative smoking exposure in current smokers is a significant risk factor for carotid atherosclerosis, while the duration of smoking cessation in former smokers is inversely associated with carotid atherosclerosis [6]. However, little has been reported on the effect of smoking on carotid plaque morphology. Plaque pathogenesis arises from complex plaque morphology, inflammation, and rupture from plaque instability $[7,8]$. Both stenotic plaque and plaque with minimal luminal effect are associated with an increased risk of incident ischemic cerebrovascular events [9]. Vulnerability of carotid plaque is conferred by increased risk to rupture and thromboembolism, and has been increasingly recognized as an important factor for identifying patients at risk for stroke or other vascular ischemic events [10].

Carotid ultrasonographic gray-scale median (GSM) is a computer-assisted index used to identify vulnerable plaques by their echodensity [11]. Histological observations have confirmed that low GSM values corresponded to echolucent plaques with features that included high lipid content, hemorrhagic areas in a necrotic core, and a thin fibrous cap, whereas high GSM index correlated to echogenic plaques of high fibrous content and calcification [12]. In a recent meta-analysis, the presence of ultrasound-determined echolucent carotid plaque was associated with an increased risk of ipsilateral stroke across all carotid stenosis severities [13]. Studies have also linked echodense plaques to greater cerebrovascular disease risk $[10,14]$. Therefore, the GSM score can help identify patients with vulnerable plaque at an increased risk of stroke.

Although extensive research has been conducted on the association of smoking with IMT, endothelial function, and carotid atherosclerosis, there is a lack of understanding of the relationship between smoking and carotid plaque morphology. The increased risk of vulnerable plaque formation is an additional pathological mechanism that needs further consideration because it may mediate stroke risk from cigarette smoking. Given that both echolucent and echodense plaques can increase cerebrovascular event risk [10,13-16], we hypothesized that current cigarette smoking is associated with increased risk of carotid plaque at all echodensity levels, but the elevation of risk would be the highest for less echogenic plaques expressed by low ultrasonographic GSM index. Therefore, we sought to determine the relationship between cigarette smoking and the risk of ultrasound-derived plaque morphology in a large, urban, multiethnic population from Northern Manhattan.

\section{Methods}

\section{Study Population}

Subjects were participants of the Northern Manhattan Study (NOMAS), an ongoing, prospective, population-based study of stroke incidence and vascular risk factors in an urban, multiethnic population [17]. Methods of NOMAS recruitment and enrollment have been previously described [18]. In brief, NOMAS enrolled 3,298 subjects who were identified by random digit dialing. Inclusion criteria were (1) age $\geq 39$ years, (2) no prior history of stroke, and (3) had resided in the Northern Manhattan area for at least 3 months with a telephone. The study was approved by the Columbia University Medical Center and the University of Miami Institutional Review Boards. All participants gave informed consent. Using a cross-sectional design, the current study is an analysis of a subsample of NOMAS participants who received carotid ultrasound and evaluation of carotid plaque morphology by GSM.

\section{Baseline Assessment of Covariates}

Baseline data were collected through interviews of the community participants using standardized data collection instruments [19] and physical and neurological examinations. Ethnicity based on race was determined through self-identification using a series of questions modeled after the US census. Baseline questionnaires included questions about cigarette smoking behavior, number of cigarettes smoked, age at which smoking started and stopped, and current smoking patterns. Cigarette pack-years were calculated as the number of years smoked multiplied by the number of cigarettes smoked per day, then divided by 20 . Hypertension was defined as systolic blood pressure (BP) $\geq 140 \mathrm{~mm} \mathrm{Hg}$ or diastolic $\mathrm{BP} \geq 90 \mathrm{~mm} \mathrm{Hg}$ or a patient's self-report of a history of hypertension or use of antihypertensive medications. Dyslipidemia was defined as cholesterol levels $>200 \mathrm{mg} / \mathrm{dl}$ or self-reported history of increased blood cholesterol levels or cholesterol-lowering medication use. Diabetes mellitus was defined as fasting blood glucose $\geq 126 \mathrm{mg} / \mathrm{dl}$ or the patient's self-report of such a history or use of insulin or hypoglycemic medications. Body mass index (BMI) was calculated in $\mathrm{kg} / \mathrm{m}^{2}$. Physical activity was defined as the frequency and duration of 14 different recreational activities during the 2 -week period before the interview, as described previously [20]. Moderate alcohol use was defined as current drinking of $>1$ drink per month and $\leq 2$ drinks per day.

\section{Assessment of Carotid Plaque GSM}

High-resolution B-mode ultrasounds (GE logIQ 700, 9- to 13$\mathrm{MHz}$ linear-array transducer) were performed by trained and certified sonographers as previously detailed [21]. Left and right carotid bifurcations and internal and common carotid arteries were 
examined for the presence of plaque. Plaque was defined as an area of focal wall thickening $50 \%$ greater than surrounding wall thickness confirmed by marking and comparing plaque thickness with the thickness of the surrounding wall during scanning by electronic calipers. After image normalization using linear scaling, GSM of an operator-selected blood region inside the vessel lumen was mapped to 0 and the brightest region of the adventitia was mapped to 255 using M'Ath (Imt, Inc., Paris, France) [22]. Both of these reference regions were approximately $0.4 \mathrm{~mm}^{2}$ in area and were selected on the first image of the image sequence. The reference GSM values calculated on the first frame were applied to that and all subsequent images. GSM was expressed for each plaque.

\section{Statistical Analysis}

For individuals with multiple carotid plaques, the GSM value was calculated as the mean GSM across the plaques, weighted by the plaque area for each plaque, such that the GSM for larger plaques contributed more to the calculation of the individual's GSM value. We examined the weighted mean GSM as a categorical variable with no plaque as the reference category. Individuals with plaque were divided into quintiles of weighted mean GSM, resulting in 6 categories of the dependent variable (quintile 1, quintile 2 , quintile 3 , quintile 4 , quintile 5 vs. no plaque). We conducted sensitivity analyses defining plaque GSM alternatively for those with multiple plaques. Specifically, the GSM in the plaque with the largest area was calculated, and those with plaque were divided into GSM quintiles and compared to no plaque as the reference category.

We used multinomial logistic regression to examine the relationship between cigarette smoking and plaque GSM categories. Cigarette smoking was modeled in 2 ways: continuously in packyears, and categorically as current smoking (in the past year from baseline assessment), former smoking, and never smoking [20]. We constructed a series of 2 models: (1) adjusted for age, sex, and race/ethnicity and (2) additionally adjusted for high school completion and vascular risk factors (moderate alcohol use, moderateheavy physical activity, BMI, systolic blood pressure, diastolic blood pressure, anti-hypertensive medication use, diabetes, LDL, HDL, cholesterol-lowering medication use, aspirin use). We added interaction terms to model 2 to examine potential effect modification by the demographic variables for the associations between cigarette smoking and weighted GSM. We also examined the association of the covariates of interest (demographic and vascular risk factors) with categories of cigarette smoking using Chi-square tests.

\section{Results}

Among 1,746 NOMAS participants, the mean age was $65.5 \pm 8.9$ years, $60 \%$ were women, $18 \%$ white, $63 \%$ Hispanic, $19 \%$ black. There were $14 \%$ current cigarette smokers, $38 \%$ former cigarette smokers, and $48 \%$ never smokers. The mean pack-years of cigarette smoking were $12.5 \pm 23.3$, and the median was 0.18 . Table 1 shows the distribution of demographic and vascular risk factors in the study population overall and stratified by cigarette smoking category. Current smoking was associated with younger age, male sex, black race, high school completion, moderate alcohol use, physical inactivity (none to light), lower BMI, no hypertension, and no dyslipidemia in univariate analyses. Carotid plaque was present in $58 \%$ of the study population, $21 \%$ with a single plaque and $37 \%$ with multiple plaques (table 2). Those who had never smoked had less plaques and smaller number of plaques than current or former smokers. Current and former smokers had very similar frequency of plaque numbers. Table 3 shows the weighted mean GSM across the GSM quintiles.

The association between cigarette smoking modeled categorically, in relation to the weighted mean GSM in the sequence of two multinomial logistic regression models is shown in table 3. Former smokers had an increased risk of having GSM in quintiles 2-5 as compared to never smokers, and odds ratios (ORs) appeared to increase with greater GSM. In contrast, the relationship for current smoking had an approximate $\mathrm{V}$-shaped-like relationship with GSM quintiles, such that current smokers had GSM more likely to be in quintiles $1,2,4$, and 5 as compared to those who never smoked, with no increase in risk for quintile 3 (fig. 1). This association was also apparent in a sensitivity analysis in which the GSM value for those with multiple plaques was calculated as that from the plaque with the largest area (data not shown). When cigarette smoking was modeled continuously in pack-years, a positive association was observed for all 5 GSM quintiles $(\mathrm{OR}=1.01 ; 95 \%$ confidence interval $(\mathrm{CI}), 1.00-1.02)$ in comparison to no plaque (data not shown). Adjustment for vascular risk factors did not substantially attenuate the associations. No interaction was observed between the demographic variables (age, sex, race/ethnicity) and the smoking variables in relation to GSM.

\section{Discussion}

In the urban multiethnic population involved in this study, current cigarette smokers were at an increased risk of having either predominately echolucent or predominantly echodense carotid plaque when compared to never smokers. This association simulates a nonlinear, V-shaped-like relationship between current cigarette smoking and plaque echodensity. Former cigarette smokers, however, had the greatest risk for echodense carotid plaque. Continuously increasing pack-years were associated with all levels of plaque echodensity. Together, these results suggested complex mechanisms that underlie the 
Table 1. Baseline demographics and vascular risk factors by cigarette smoking status among 1,743 individuals from the Northern Manhattan study, n (\%)

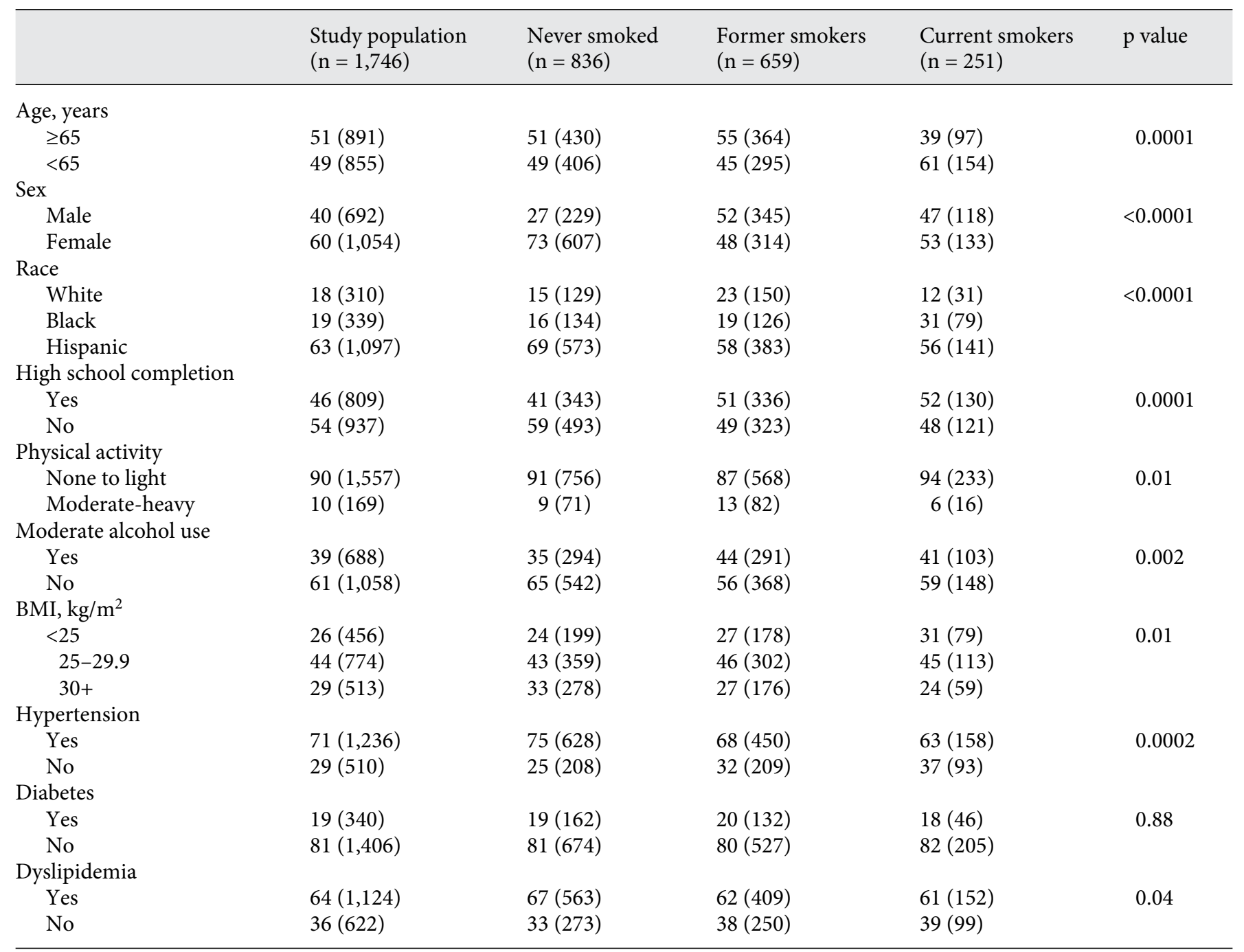

cumulative burden of smoking and benefits of smoking cessation with carotid plaque morphology.

GSM is an ultrasonographic measure of plaque echodensity that closely relates to plaque histological morphology $[11,12,23,24]$. Low GSM values correspond to predominately echolucent plaques that are lipid-rich with thin fibrous caps susceptible to rupture by hemodynamic shear stress and local macrophage activity [25]. Echolucent plaques have been associated with increased risk of stroke [26-28]. In a recent meta-analysis of 7 studies including 7,557 subjects with a mean follow-up of 37.2 months, predominately echolucent carotid plaques were associated with an increased risk of ipsilateral stroke regardless of the stenosis severity [13]. Plaque echolucency

Cigarette Smoking and Carotid Plaque

Echodensity in the NOMAS
Table 2. Plaque number frequency by smoking category, $\%$

\begin{tabular}{llll}
\hline $\begin{array}{l}\text { Number } \\
\text { of plaques }\end{array}$ & $\begin{array}{l}\text { Never smoked } \\
(\mathrm{n}=836)\end{array}$ & $\begin{array}{l}\text { Former } \\
\text { smokers } \\
(\mathrm{n}=659)\end{array}$ & $\begin{array}{l}\text { Current } \\
\text { smokers } \\
(\mathrm{n}=251)\end{array}$ \\
\hline 0 & 48 & 37 & 37 \\
1 & 21 & 20 & 21 \\
2 & 15 & 17 & 18 \\
3 & 8 & 11 & 10 \\
4 & 4 & 7 & 6 \\
5 & 3 & 4 & 4 \\
6 & 1 & 2 & 2 \\
7 & $<1$ & $<1$ & 2 \\
8 & 0 & $<1$ & 1 \\
9 & 0 & $<1$ & 0 \\
\hline
\end{tabular}


Table 3. Cigarette smoking and plaque morphology: multinomial logistic regression models of cigarette smoking variables in relation to carotid plaque GSM quintiles

\begin{tabular}{|c|c|c|c|c|c|}
\hline $\begin{array}{l}\text { Quintile of } \\
\text { weighted } \\
\text { mean GSM vs. } \\
\text { no plaque }\end{array}$ & $\mathrm{n}$ & $\begin{array}{l}\text { Mean-weighted } \\
\text { density } \pm \text { SD }\end{array}$ & Range & $\begin{array}{l}\text { OR }(95 \% \mathrm{CI}) \text { f or } \\
\text { former smoking } \\
\text { vs. never smoking }\end{array}$ & $\begin{array}{l}\text { OR }(95 \% \text { CI) for } \\
\text { current smoking } \\
\text { vs. never smoking }\end{array}$ \\
\hline \multicolumn{6}{|l|}{ Quintile 1 } \\
\hline Model 1 & 200 & $48 \pm 9$ & $17.00-60.84$ & $1.13(0.78-1.62)$ & $2.11(1.33-3.35)$ \\
\hline Model 2 & & & & $1.05(0.72-1.55)$ & $2.17(1.34-3.52)$ \\
\hline \multicolumn{6}{|l|}{ Quintile 2} \\
\hline Model 1 & 198 & $72 \pm 7$ & $61.00-82.58$ & $1.41(0.98-2.03)$ & $2.23(1.39-3.57)$ \\
\hline Model 2 & & & & $1.46(1.00-2.12)$ & $2.33(1.42-3.83)$ \\
\hline \multicolumn{6}{|l|}{ Quintile 3} \\
\hline Model 1 & 206 & $90 \pm 4$ & $83.00-97.15$ & $1.43(1.01-2.02)$ & $1.17(0.70-2.01)$ \\
\hline Model 2 & & & & $1.56(1.09-2.24)$ & $1.18(0.67-2.10)$ \\
\hline \multicolumn{6}{|l|}{ Quintile 4} \\
\hline Model 1 & 202 & $105 \pm 5$ & $97.17-113.00$ & $1.61(1.12-2.32)$ & $2.12(1.28-3.51)$ \\
\hline Model 2 & & & & $1.66(1.13-2.42)$ & $2.05(1.19-3.51)$ \\
\hline \multicolumn{6}{|l|}{ Quintile 5} \\
\hline Model 1 & 202 & $128 \pm 12$ & $113.09-164.00$ & $1.71(1.19-2.32)$ & $2.12(1.30-3.48)$ \\
\hline Model 2 & & & & $1.73(1.19-2.51)$ & $2.13(1.27-3.56)$ \\
\hline
\end{tabular}

Model 1: adjusted for age, sex, and race/ethnicity.

Model 2: adjusted for age, sex, race/ethnicity, education, alcohol use, physical activity, BMI, systolic blood pressure, diastolic blood pressure, anti-hypertensive medication use, diabetes, LDL, HDL, cholesterol-lowering medication use, aspirin use.

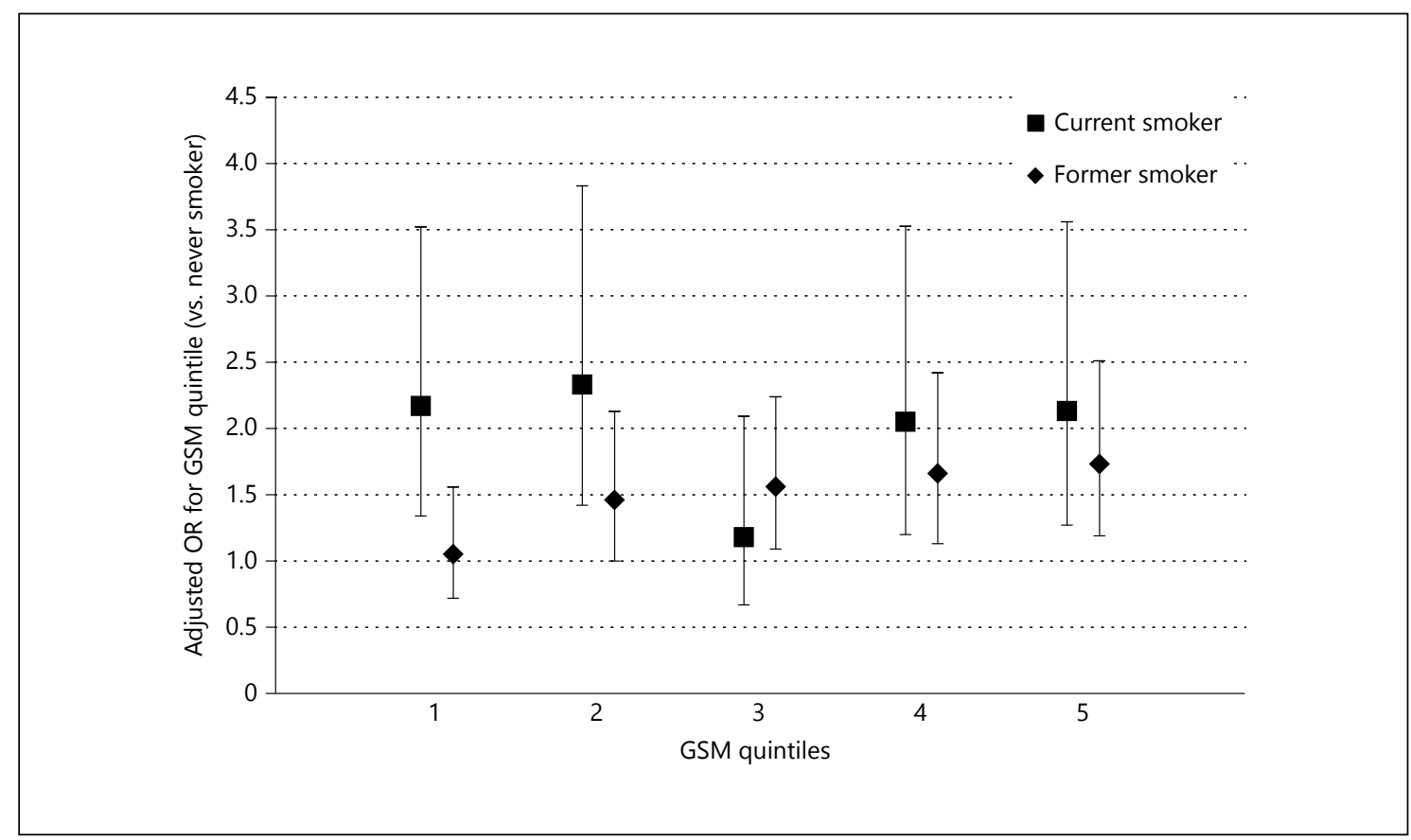

Fig. 1. Adjusted OR of cigarette smoking variables (current and former smokers) in relation to mean-weighted carotid plaque GSM quintiles. 
was also shown to improve selection and risk stratification of patients undergoing carotid endarterectomy or stenting [15] and to monitor for plaque stabilization after statin treatment [29]. High GSM values represent echodense plaques with more fibrous and calcified content [12]. Echodense plaques are more likely to be found in asymptomatic patients with carotid stenosis and their association with stroke risk is less clear [30]. Thickened fibrous cap reduces proximity of the necrotic core to the vessel lumen and circulating thrombus-forming agents to provide a protective effect [28]. However, some studies have suggested differential shear stress and cap tension from micro-calcifications of a heterogeneously structured plaque [31-33]. Calcified nodules were present within close proximity to the luminal surface risk extruding through and rupturing the cap [10]. Additionally, calcified carotid plaque may be a marker of an active atherosclerotic process in other arterial segments or vascular beds, and therefore may be associated with increased risk of CVD [16].

Cigarette smoke exposure adversely affects all stages of plaque formation that involve endothelial dysfunction leading to increased thrombogenicity of the artery wall [1]. Stable aldehydes in cigarette smoke contribute to volatile free radical generation that impairs endothelial ability to maintain cellular levels of nitric oxide and triggers an inflammatory cascade [34]. Chronic inflammation can damage endothelial cells to expose subendothelial matrix to circulating thrombogenic factors [35]. Nicotine and smoke exposure further complicate thrombus formation by precipitating factors that may mediate plaque vulnerability. These factors include increased activity of metalloproteinases that degrade extracellular matrix of plaque caps [36], macrophage infiltration from systemic inflammation [37], immature vessel formation prone to hemorrhage [38], and increased plaque thrombogenicity from expression of tissue factor [39]. These processes may underlie our reported associations of smoking with a wide range of the plaque GSM levels, depending on the chronicity and type of the arterial wall injury and dysfunction.

We also reported an increased risk of higher GSM plaque, but not lower GSM plaque, among former smokers when compared to never smokers. Previous studies reported benefits for reduction of carotid IMT and lumen diameter with smoking cessation $[5,6]$ but have not examined the effects of smoking cessation on plaque morphology. Additionally, our data showed similar associations across all GSM levels with increasing pack-years, indicating the cumulative effects of smoking on all types of plaque morphology with their potential risk for stroke as previously demonstrated $[3,6,8]$. Although we could not

Cigarette Smoking and Carotid Plaque

Echodensity in the NOMAS examine a temporal trend in our analysis, the different relationships between smoking and the plaque GSM levels highlighted complex changes in plaque morphology with cumulative smoking exposure as well as with smoking cessation that warrant further investigation.

Strengths of our study included the population-based design and diverse ethnic population, which made our results more generalizable for multiethnic populations. Further, in busy clinical settings or large epidemiological studies, the ultrasound protocol of measuring IMT may be too time-consuming and expensive, whereas techniques of imaging of carotid plaque may be easier and more costeffective. Our analyses determined a mean GSM value weighted by plaque area, providing a single GSM value for individuals with multiple plaques that may better represent the plaque morphology dominance in their arteries. This is both a strength and a weakness, as it involves some degree of misclassification of individuals with multiple plaques of varying echodensity. Specifically, individuals with both low and high GSM plaques may be classified in the intermediate GSM range when in reality they have both echolucent and echodense plaque and therefore may be at greatest risk due to vulnerable plaque presence. However, our results did not change in our sensitivity analyses in which the GSM value for those with multiple plaques or plaques with the largest areas were analyzed.

Perhaps the most important limitation is that the analysis is cross-sectional, limiting inferences about temporality and causality. Further limitations included our relatively small sample size for current smokers, which may have restricted the detection of a significant association with GSM quintile 3. However, the V-shaped relationship is still supported by the fact that the effect estimate for current smokers (vs. never smokers) in relation to GSM quintile 3 was below the $95 \%$ CI range for quintiles 1, 2, 4 , and 5. In addition, cigarette smoking information was assessed by self-report and therefore some degree of misclassification is possible. Residual confounding by unmeasured vascular risk factors is also a potential source of bias. We observed no effect modification by demographic variables, including age, sex, and race/ethnicity, for the association between smoking and plaque GSM. However, the power to detect significant interactions was limited. Related studies have reported varying results in effect modification by sex for the association between carotid atherosclerosis progression and smoking [40, 41]. Additionally, we recently highlighted several novel genetic variants that may modify the effect of smoking on carotid plaque burden in Hispanics [42]; therefore, further study is needed in other heterogeneous cohorts. 
Cigarette smoking may lead to carotid plaque morphology at greatest risk for cerebrovascular events. With growing evidence of GSM being a simple and noninvasive marker of carotid plaque vulnerability, longitudinal investigations are needed to assess the relationship between cigarette smoking and plaque echodensity to better understand how cigarette smoking influences plaque morphology, and results in vascular events.

\section{Sources of Funding}

Supported by National Institute of Neurological Disorders and Stroke grant R37 NS 29993.

\section{Disclosures Statement}

The authors have no conflict of interest to declare.

\section{References}

1 Csordas A, Bernhard D: The biology behind the atherothrombotic effects of cigarette smoke. Nat Rev Cardiol 2013;10:219-230.

2 Howard G, Wagenknecht LE, Burke GL, DiezRoux A, Evans GW, McGovern P, et al: Cigarette smoking and progression of atherosclerosis: the atherosclerosis risk in communities (ARIC) study. JAMA 1998;279:119-124.

3 Celermajer DS, Sorensen KE, Georgakopoulos D, Bull C, Thomas O, Robinson J, et al: Cigarette smoking is associated with dose-related and potentially reversible impairment of endothelium-dependent dilation in healthy young adults. Circulation 1993;88:2149-2155.

4 Jha P, Ramasundarahettige C, Landsman V, Rostron B, Thun M, Anderson RN, et al: 21stcentury hazards of smoking and benefits of cessation in the United States. N Engl J Med 2013;368:341-350.

5 Peters SA, Huxley RR, Woodward M: Smoking as a risk factor for stroke in women compared with men: a systematic review and meta-analysis of 81 cohorts, including 3,980,359 individuals and 42,401 strokes. Stroke 2013; 44:2821-2828.

6 Kweon SS, Lee YH, Shin MH, Choi JS, Rhee JA, Choi SW, et al: Effects of cumulative smoking exposure and duration of smoking cessation on carotid artery structure. Circ J 2012;76:2041-2047.

7 Gomez RG: Carotid plaque morphology and risk for stroke. Stroke 1990;21:148-151.

8 Glagov S, Zarins CB: What are the determinants of plaque instability and its consequences? J Vasc Surg 1989;9:389-390.

9 Rundek T, Arif H, Boden-Albala B, Elkind MS, Paik MC, Sacco RL: Carotid plaque, a subclinical precursor of vascular events: the Northern Manhattan study. Neurology 2008; 70:1200-1207.

10 Naghavi M, Libby P, Falk E, Casscells SW, Litovsky S, Rumberger J, et al: From vulnerable plaque to vulnerable patient: a call for new definitions and risk assessment strategies: part I. Circulation 2003;108:1664-1672.

11 Sztajzel R, Momjian S, Momjian-Mayor I, Murith N, Djebaili K, Boissard G, et al: Stratified gray-scale median analysis and color mapping of the carotid plaque: correlation with endarterectomy specimen histology of 28 patients. Stroke 2005;36:741-745.
12 El-Barghouty NM, Levine T, Ladva S, Flanagan A, Nicolaides A: Histological verification of computerised carotid plaque characterisation. Eur J Vasc Endovasc Surg 1999;11:414416.

13 Gupta A, Kesavabhotla K, Baradaran H, Kamel H, Pandya A, Giambrone AE, et al: Plaque echolucency and stroke risk in asymptomatic carotid stenosis: a systematic review and meta-analysis. Stroke 2015;46:91-97.

14 AbuRahma AF, Wulu JT Jr, Crotty B: Carotid plaque ultrasound heterogeneity and severity of stenosis. Stroke 2002;33:1772-1775.

15 Biasi GM, Froio A, Diethrich EB, Deleo G, Galimberti S, Mingazzini P, et al: Carotid plaque echolucency increases the risk of stroke in carotid stenting: the Imaging in carotid angioplasty and risk of stroke (ICAROS) study. Circulation 2004;10:756-762.

16 Prabhakaran S, Singh R, Zhou X, Ramas R, Sacco RL, Rundek T: Presence of calcified carotid plaque predicts vascular events: the Northern Manhattan study. Atherosclerosis 2007;195:e197-e201.

17 Sacco RL, Boden-Albaba B, Gan R, Chen X, Kargman DE, Shea S, et al: Stroke incidence among white, black, and Hispanic residents of an urban community: the Northern Manhat$\tan$ stroke study. Am J Epidemiol 1998;147: 259-268.

18 White H, Boden-Albala B, Wang C, Elkind MS, Rundek T, Wright CB, et al: Ischemic stroke subtype incidence among whites, blacks, and hispanics: the Northern Manhattan study. Circulation 2005;111:13271331.

19 Gentry EM, Kalsbeek WD, Hogelin GC, Jones JT, Gaines KL, Forman MR, et al: The behavioral risk factor surveys: II. Design, methods, and estimates from combined state data. Am J Prev Med 1985;1:9-14.

20 Willey JZ, Moon YP, Paik MC, Boden-Albaba B, Sacco RL, Elkind MS: Physical activity and risk of stroke in the Northern Manhattan study. Neurology 2009;73:1774-1779.

21 Rundek T, Hundle R, Ratchford E, Ramas R, Sciacca R, Di Tullio MR, et al: Endothelial dysfunction is associated with carotid plaque: a cross-sectional study from the population based Northern Manhattan study. BMC Cardiovasc Disord 2006;17:35.
22 Kuo F, Gardener H, Dong C, Cabral D, DellaMorte D, Blanton SH, et al: Traditional cardiovascular risk factors explain the minority of the variability in carotid plaque. Stroke 2012;43:1755-1760.

23 Matsagas MI, Vasdekis SN, Gugulakis AG, Lazaris A, Foteinou M, Sechas MN: Computer-assisted ultrasonographic analysis of carotid plaques in relation to cerebrovascular symptoms, cerebral infarction, and histology. Ann Vasc Surg 2000;14:130-137.

24 Tegos TJ, Sohail M, Sabetai MM, Robless P, Akbar N, Pare G, et al: Echomorphologic and histopathologic characteristics of unstable carotid plaques. ANJR Am J Neuroradiol 2000; 21:1937-1944.

25 Singh AS, Atam V, Jain N, Yathish BE, Patil MR, Das L: Association of carotid plaque echogenicity with recurrence of ischemic stroke. N Am J Med Sci 2013;5:371-376.

26 Polak JF, Shemanski L, O'Leary DH, Lefkowitz D, Price TR, Savage PJ, et al: Hypoechoic plaque at US of the carotid artery: an independent risk factor for incident stroke in adults aged 65 years or older. Radiology 1998;208: 649-654.

27 Grønholdt ML, Nordestgaard BG, Schroeder TV, Vorstrup S, Sillesen H: Ultrasonic echolucent carotid plaques predict future strokes. Circulation 2001;104:68-73.

28 Bassiouny HS, Sakaguchi Y, Mikucki SA, McKinsey JF, Piano G, Gewertz BL, et al: Juxtalumenal location of plaque necrosis and neoformation in symptomatic carotid stenosis. J Vasc Surg 1997;26:585-594.

29 Della-Morte D, Moussa I, Elkind MS, Sacco RL, Rundek T: The short-term effect of atorvastatin on carotid plaque morphology assessed by computer-assisted gray-scale densitometry: a pilot study. Neurol Res 2011;33: 991-994.

30 Grogan JK, Shaalan WE, Cheng H, Gewertz B, Desai T, Schwarze G, et al: B-mode ultrasonographic characterization of carotid atherosclerotic plaques in symptomatic and asymptomatic patients. J Vasc Surg 2005;42:435-441.

31 Tegos TJ, Stavropoulos P, Sabetai MM, Khodabakhsh P, Sassano A, Nicolaides AN: Determinants of carotid plaque instability: echoicity versus heterogeneity. Eur J Vasc Endovasc Surg 2001;22:22-30. 
32 Falk E, Shah PK, Fuster V: Coronary plaque disruption. Circulation 1995;92:657671.

33 Rambhia SH, Liang X, Xenos M, Alemu Y, Maldonado N, Kelly A, et al: Microcalcifications increase coronary vulnerable plaque rupture potential: a patient-based micro-CT fluid-structure interaction study. Ann Biomed Eng 2012;40:1443-1454.

34 Barua RS, Ambrose JA, Srivastava S, DeVoe MC, Eales-Reynolds LJ: Reactive oxygen species are involved in smoking-induced dysfunction of nitric oxide biosynthesis and upregulation of endothelial nitric oxide synthase: an in vitro demonstration in human coronary artery endothelial cells. Circulation 2003;107:2342-2347.

35 Bernhard D, Csordas A, Henderson B, Rossmann A, Kind M, Wick G: Cigarette smoke metal-catalyzed protein oxidation leads to vascular endothelial cell contraction by depo- lymerization of microtubules. FASEB J 2005; 19:1096-1107.

36 Carty CS, Soloway PD, Kayastha S, Bauer J, Marsan B, Ricotta JJ, et al: Nicotine and cotinine stimulate secretion of basic fibroblast growth factor and affect expression of matrix metalloproteinases in cultured human smooth muscle cells. J Vasc Surg 1996;24: 927-934.

37 Kangavari S, Matetzky S, Shah PK, Yano J, Chyu KY, Fishbein MC, et al: Smoking increases inflammation and metalloproteinase expression in human carotid atherosclerotic plaques. J Cardiovasc Pharmacol Ther 2004;9: 291-298.

38 Csordas A, Kreutmayer S, Ploner C, Braun PR, Karlas A, Backovic A, et al: Cigarette smoke extract induces prolonged endoplasmic reticulum stress and autophagic cell death in human umbilical vein endothelial cells. Cardiovasc Res 2011;92:141-148.
39 Matetzky S, Tani S, Kangavari S, Dimayuga P, Yano J, Xu H, et al: Smoking increases tissue factor expression in atherosclerotic plaques: implications for plaque thrombogenicity. Circulation 2000;102:602-604.

40 Alsulaimani S, Gardener H, Elkind MS Cheung K, Sacco RL, Rundek T: Elevated homocysteine and carotid plaque area and densitometry in the Northern Manhattan study. Stroke 2013;44:457-461.

41 Fan AZ, Paul-Labrador M, Merz CN, Iribarren C, Dwyer JH: Smoking status and common carotid artery intima-medial thickness among middle-aged men and women based on ultrasound measurement: a cohort study. BMC Cardiovasc Disord 2006;6:42.

42 Della-Morte D, Wang L, Beecham A, Blanton $\mathrm{SH}$, Zhao H, Sacco RL, et al: Novel genetic variants modify the effect of smoking on carotid plaque burden in hispanics. J Neurol Sci 2014;344:27-31. 